\title{
Internal mammary node management in breast cancer. A review
}

\author{
David Vrana a,c,d, Jiri Gatek ${ }^{b}$, Karel Cwiertkaa , Lucie Lukesovaa ${ }^{a}$ Pavel Koranda ${ }^{\mathrm{e}}$
}

\begin{abstract}
Background. Internal mammary nodes visualized during sentinel node biopsy for breast cancer, remain an unresolved management issue. Further, both internal mammary node (IMN) radiotherapy and biopsy have attendant risks and hence should be used with caution. The purpose of this review is to highlight the available data and evidence.

Methods and Results. A PubMed database from 1960 to 2012 using key words: internal mammary nodes, breast cancer radiotherapy planning, adjuvant radiotherapy, sentinel node biopsy in breast cancer and selected publications on the significance of internal mammary nodes in breast cancer treatment, published data and approaches used.

We found 14513 relevant papers and we selected 30 that clearly investigated the management of internal mammary nodes during sentinel node search. We focused on the incidence of IMN metastasis (6 papers), risk factors associated with IMN drainage (9 reports), management of IMN and the impact on disease free and overall patient survival (15 papers).
\end{abstract}

Conclusions. The evidence for breast cancer axillary nodes management is good but the data for other draining nodes such as internal mammary nodes are far less conclusive and further research is needed.

Key words: internal mammary nodes, breast cancer, radiotherapy, sentinel node

Received: May 18, 2013; Accepted with revision: September 11, 2013; Available online: September 13, 2013

http://dx.doi.org/10.5507/bp.2013.068

\author{
${ }^{a}$ Department of Oncology, Faculty of Medicine and Dentistry, Palacky University Olomouc, Czech Republic \\ ${ }^{b}$ Department of Surgery, Atlas Hospital and Tomas Bata University in Zlin \\ 'Institute of Molecular and Translational Medicine, Faculty of Medicine and Dentistry, Palacky Universit Olomouc and University Hospital \\ Olomouc \\ ${ }^{d}$ Toxicogenomics Unit, National Institute of Public Health, Prague \\ eDepartment of Nuclear Medicine, Faculty of Medicine and Dentistry, Palacky University Olomouc \\ Corresponding author:David Vrana, e-mail:davvrana@gmail.com
}

\section{INTRODUCTION}

Breast cancer is the most common cancer in women worldwide. However, improved patient care is leading to better outcomes and unchanged or reduced mortality in many countries. The reason for this may be new treatment targeted therapy, improved surgical procedures (resection margin and sentinel node biopsy) and radiotherapy techniques that preserve at-risk organs (intensity modulating radiotherapy, active breathing control). However, there are still areas where current approaches are inadequate and clear recommendations are not available. One of these is sentinel node detection, more specifically the problem of internal mammary node (IMN) detection during axillary sentinel node biopsy. The sentinel node procedure is based on the assumption that the first node detected is at highest risk for metastasis and that pathologic examination of the node, in the case of negativity, can be omitted with all the consequences of avoiding the increased risks of arm edema after axillary node dissection ${ }^{1-4}$. There is some consensus regarding axillary node procedures during sentinel node detection and adjuvant radiotherapy. However, the situation is different in the case when the radiocoloid flow is directed to higher axillary node levels (level III or infraclavicular nodes, supraclavicular nodes) and in the case of internal mammary node detection ${ }^{5-11}$. Cox et al. ${ }^{12}$ provided some recommendations for IMN management in 1960. The situation now is very different; the surgical procedure for sampling internal mammary nodes carries the risk of bleeding, the procedure is longer and demands on surgical experience greater. Involvement of internal mammary lymph nodes is associated with poor prognosis ${ }^{13-16}$. However, there are a number of options for managing internal mammary nodes visualized during sentinel node sampling. The first is the IMN sampling mentioned above with all the potential consequences of the procedure, the second is to perform PET/CT or other imaging technique (ultrasound, MRI) to check for possible macroscopic disease. In this case, we have to take into account that any imaging technique will only detect tumors larger than $5 \mathrm{~mm}$ and in the case of internal mammary node sampling, it is clear that the majority of these node metastases are microscopic. Uninvolved IMN are usually around $4 \mathrm{~mm}$ in diameter. In general, imaging techniques do not appear appropriate for resolving the issue. The last option is to irradiate all such patients and finally there is also the option to ignore the IMN. However, in this case, patients can be understaged and consequently undertreated. As IMN are detected in only about $20-25 \%$ of cases during sentinel node detection, is it acceptable to radiate the internal mammary chain in $25 \%$ of all breast cancer patients? The reason for our concerns about internal mammary node irradiation is the possible consequences of radiotherapy. Radiotherapy may 
reduce the number of local recurrences but due to the unavoidable radiation of healthy tissues and organs, we can cause acute (within 90 days), late and very late effects on these organs. We are aware, from extensive experience, of the acute effects of radiotherapy, such as skin erythema, pericarditis and acute pneumonitis. While new treatment modalities such as intensity modulated radiotherapy and respiratory tracking, can significantly reduce the risk of acute effects, the situation is different in the case of late effects (occurring more than 90 days after radiotherapy completion). There are no clear recommendations about late effects or dose limits for external radiotherapy. In the case of adjuvant breast cancer radiotherapy, we are talking about heart ${ }^{17}$, lung and the contralateral breast as organs at risk in radiotherapy planning (other organs like brachial plexus, thyroid gland and skin have to be considered in certain situations as well). In the case of the heart, the recommended dose limit for acute pericarditis is V40 less than $40 \%$. However, in cardiomyopathy and coronary artery disease, the dose limits are much less defined $^{18-23}$. There are limited data on possible delayed effects and further research is needed to set the limits for radiotherapy treatment purposes. The foregoing makes it clear that IMN radiotherapy may significantly increase the risk of heart radiotherapy delayed effects and the indication should be carefully considered. The reader should understand that all our considerations are based on the situation when IMNs are not macroscopically positive (clinically, on PET or CT). In the latter case, radio and chemotherapy would be clearly indicated.

\section{Incidence of IMN drainage and IMN metastasis}

First, we focused on the prevalence of IMN metastasis and predictive factors for IMN involvement, aiming to select a subgroup of patients who could benefit from IMN radiotherapy or IMN biopsy. The incidence of IMN drainage is about $20 \%$ and of these in about $20 \%$, metastasis are found during the biopsy. Hence, it follows that the incidence of IMN metastasis in breast cancer patients is around $4-6 \%$. However, in some subgroups of patients it may be $28-52 \%$. Heuts et al. ${ }^{24}$ evaluated the probability of pathologic positivity of IMN in the case of lymphoscintigraphic drainage into these nodes. Internal mammary nodes were detected in $20 \%$ of cases (196/1008). IMN sampling was performed in 139 cases and metastasis were found in $31(22 \%)$ cases $(31 / 139)$ showing that patients with IMN drainage have a significant risk for metastasis. In contrast to this high positivity ratio, Veronesi et al. ${ }^{25}$ evaluated 663 breast cancer patients of whom 68 had metastasis in IMN (10.3\%). Farrus et al. ${ }^{26}$ reported $14 \%$ positivity rate of IMN in patients with early stage breast cancer. Considering these different frequencies of IMN involvement there is a clear need to identify predictive factors which could select a subgroup of patients who could benefit from more extensive staging or adjuvant radiotherapy and chemotherapy. IMN metastasis without ALN metastasis is rarely found in early stage breast cancer according to Ramsay et al. ${ }^{27}$. Using certain combinations of risk factors, the incidence of metastasis in IMN could be $44-65 \%$ (ref. $^{28-29}$ ).

\section{Factors associated with IMN drainage and metastasis}

Coombs et al. ${ }^{30}$ described possible risk factors for internal mammary chain involvement. Drainage into IMN was detected in $18.4 \%(90 / 490)$. Of the $18.4 \%$, metastasis was confirmed in $22.2 \%$ or about $4 \%$. The risk factors for IMN involvement were: age under 35 years, tumor grading and lymphovascular invasion. The same problem was investigated by Hyndié et al. ${ }^{31}$ who evaluated studies including more than 300 breast cancer patients where in cases of IMN drainage, internal mammary nodes sampling was performed. After review of 6 studies altogether 3,876 patients, these authors found that IMN drainage was present in 792 patients (20.4\%). IMN biopsy was completed in 644 patients and this revealed IMN metastasis in 111 cases $(17.2 \%)$. After statistical review, the pathologic positivity was associated with lateral quadrants of the breast, contrasting with the generally accepted rule that IMN drainage is much more often in inner quadrants and hence may not be correct. The strongest predictive factor for IMN involvement was positivity of axillary nodes $(P<0.00001)$. Zeng et al. ${ }^{32}$ evaluated 88 breast cancer patients with internal mammary node sampling and concluded that histological grade and lymphovascular invasion status were associated with micrometastasis in the IMN $(P=0.018$ and 0.001$)$. Postma et al. ${ }^{33}$ sampled 107 IMN with lymphoscintigraphy drainage into these nodes. In 14 cases, the IMN were pathologically positive for metastasis (13\%). Leidenius et al. ${ }^{34}$ evaluated internal mammary nodes in 138 patients (out of $844,14 \%$ cases). Drainage was more often found in patients with mediocentral tumors ( 81 of $399 ; 20 \%$ ), tumors in lateral quadrants ( 56 of $585 ; 10 \% ; P<0.0001$ ) and patients without axillary metastasis (17\% compared with $10 \%$ with metastasis $P=0.0006)\left(\right.$ ref. $\left.{ }^{34}\right)$. Galimberti et al. ${ }^{35}$ sampled internal mammary nodes in 160 patients. In 146 cases $(94.4 \%)$ internal mammary nodes were negative and in 14 (8.8\%) metastasis was found. Of these 14 cases, 10 had positive axillary nodes at the same time, confirming again that axillary node positivity in the case of drainage to IMN is a strong predictive factor for IMN metastasis. Van der Ent et al. ${ }^{36}$ investigated internal mammary chain metastasis in 256 patients. This paper reported IMN metastasis in $26.8 \%(11 / 41)$. The metastases in IMN were associated with axillary node positivity. IMN metastasis without axillary metastases were detected in only $7.3 \%$ (3/41). Huang et al. ${ }^{37}$ evaluated IMN in 1,679 Chinese patients. Their conclusion was that there are certain groups of patients defined by a risk factor combination with higher than $20 \%$ risk for internal mammary node involvement: patients with more than three positive axillary lymph nodes, location of the tumor in medial quadrants and positive axillary lymph nodes, patients with tumors larger than $5 \mathrm{~cm}$ and age under 35 years, patients with tumors larger than $2 \mathrm{~cm}$ and positive axillary lymph nodes at the same time, patients with tumors larger than $2 \mathrm{~cm}$ and located in medial quadrants. These findings point again to the conclusion that ALN involvement is an important predictive factor for IMN involvement ${ }^{38}$. IMN drainage and/or positivity data are summarized in Table 1. 
Table 1. Risk factors associated with IMN drainage and/or pathologic positivity.

\begin{tabular}{|c|c|c|}
\hline Author & $\begin{array}{l}\text { Number } \\
\text { of patients }\end{array}$ & Risk factors for IMN drainage and/or presence of metastasis \\
\hline Coombs NJ et al. 2009 & 90 & Age $<35$ years, tumor grade and lymphovascular invasion \\
\hline Hyndie E et al. 2012 & 3,876 & Axillary lymph node positivity \\
\hline Zeng J et al. 2012 & 88 & Lymphovascular invasion \\
\hline Postma EL et al. 2012 & 486 & Smaller tumor size, non-palpability and a medial localization of the tumor \\
\hline Leidenus et al. 2006 & 138 & Location of the tumor mediocentral and laterally, negative axillary nodes \\
\hline van der Ent FW et al. 2001 & 256 & Axillary lymph node positivity \\
\hline Huang $\mathrm{O}$ et al. 2007 & 1,679 & $\begin{array}{l}\text { Four or more positive axillary lymph nodes, patients with medial tumor and } \\
\text { positive axillary lymph nodes, patients with T3 tumor and age under } 35 \text { years, } \\
\text { patients with T2 tumor and positive ALN, patients with T2 tumor and medial } \\
\text { tumor }\end{array}$ \\
\hline Paredes P et al. 2005 & 55 & Location of the tumors in the inner quadrants \\
\hline
\end{tabular}

\section{Management of IMN and impact on disease-free and overall patient survival-the evidence}

Zhang et al. ${ }^{39}$ went a step further to determine if there were imaging techniques that could be used for detecting positive IMN in a high risk group of patients with clinical $\mathrm{N} 2$ and N3. These authors used ultrasound, computed tomography, positron emission tomography/CT, and/or magnetic resonance imaging to identify $112 / 809$ patients who presented with clinically positive internal mammary node disease (13.8\%). Using these imaging techniques, we could avoid the higher morbidity during IMN sampling. Some physicians also stress however that lymph drainage is highly dependent on IMN radiocoloid injection technique. Paredes et al. ${ }^{40}$ investigated internal mammary chain involvement in 369 patients of whom IMN was detected in 55 cases. In the case of subdermal injection, there was no drainage into IMN found. However, in the case of peritumoral injection, drainage was found in $15.9 \%$ and in $17.6 \%$ after intratumoral injection. The predictive factor for internal mammary chain drainage was location of the tumors in the inner quadrants $(P<0.001)$. There are also data supporting the negative prognostic value of location of tumor in the inner quadrant ${ }^{41-42}$. This difference may be explained by lymph drainage to internal mammary nodes which are usually omitted during breast cancer patient staging and treatment. Several trials have failed to prove the advantage of surgical dissection of IMN for disease- free and overall survival ${ }^{43-44}$. As mentioned, the survival benefit is often not clear and patients may be exposed to unnecessary treatment and side-effects. There are few studies that have evaluated the benefit of IMN radiotherapy in the case of the absence of macroscopic disease in IMN as disease- free and overall patient survival. The data presented by Veronesi et al. have already been mentioned. Olson et al. ${ }^{45}$ recently focused on this problem to determine the significance of radiating internal mammary nodes during adjuvant therapy. Nodepositive for metastasis or T3/4 invasive breast cancer patients were included in the study. Altogether there were
2413 breast cancer patients. $41 \%$ had IMN included in the radiation field. After a median follow up of 6.2 years, the 5 -year disease- free survival for patients with IMN radiotherapy and without the radiotherapy was $82 \%$ vs. $82 \%$ $(P=0.82)$, overall survival $85 \%$ vs. $83 \%(P=0.06)$ allowing us to conclude that no statistically significant difference in survival was achieved by radiating IMN. Fowble et al. ${ }^{46}$ irradiated internal mammary nodes in 114 stage I and II breast cancer patients and compared them to 1269 who did not. After 5 and 10 years follow- up there was no significant difference found in locoregional recurrence or metastasis. No difference was found for overall survival either. Kong et al. ${ }^{47}$ found 334 patients with IMN drainage after a database research at the University of Texas MD Anderson Cancer Center between 1996 to 2005. On statistical analysis, no difference in overall survival was found. Stemmer et al. ${ }^{48}$ investigated the outcome of high risk stage II and III breast cancer patients with or without IMN treatment. After 77 months of follow-up, the diseasefree survival of the patients with IMN irradiation was increased ( $73 \%$ versus $52 \%$; $P=0.02$ ). However, no statistically significant difference was found for overall survival (OS; 78\% versus $64 \%$; $\mathrm{P}=0.08$ ). No overall survival differences were reported either by Koo et al. ${ }^{49}$, Fisher et al. ${ }^{50}$, and Arriagada et al. ${ }^{51}$. Overall survival and disease free survival are summarized in Tables 2 and 3.

\section{CONCLUSION}

There are no recommendations available on managing internal mammary nodes during sentinel nodes detection even if metastases to IMN are associated with poor prognosis. We always have to weigh the benefits of radiotherapy against local and distant recurrence and balance this against possible late effects caused by adjuvant treatment, especially considering the longer over-all survival of the breast cancer population, caused not only by better treatment but also due to improving prevention and treatment 
Table 2. Impact of IMN radiotherapy on DFS and OS.

\begin{tabular}{llllll}
\hline Author & $\begin{array}{l}\text { Number of patients } \\
\text { (IMN radiotherapy/ } \\
\text { total number) }\end{array}$ & Stage of the disease & Follow up & DFS impact & Survival impact \\
\hline $\begin{array}{l}\text { Olson RA et al. } \\
2012\end{array}$ & $981 / 2413$ & $\begin{array}{l}\text { Node-positive } \\
\text { or T3/4N0 }\end{array}$ & $\begin{array}{l}\text { Median } \\
74.4 \text { months }\end{array}$ & $\begin{array}{l}82 \% \text { vs. } 82 \% \\
(P=0.82)\end{array}$ & $\begin{array}{l}85 \% \text { vs. } 83 \% \\
(P=0.06)\end{array}$ \\
$\begin{array}{l}\text { Fowble B et al. } \\
2000\end{array}$ & $114 / 1383$ & Stage I and II & $\begin{array}{l}60 \text { and } \\
120 \text { months }\end{array}$ & No difference & No difference \\
$\begin{array}{l}\text { Stemmer SM et al. } \\
2003\end{array}$ & 100 & Stage II-III & $\begin{array}{l}\text { Median } \\
77 \text { months }\end{array}$ & $\begin{array}{l}73 \% \text { v 52\% } \\
(P=0.02)\end{array}$ & $\begin{array}{l}78 \% \text { v } 64 \% \\
(P=0.08)\end{array}$ \\
\hline
\end{tabular}

Table 3. Impact of IMN drainage on OS.

\begin{tabular}{llll}
\hline Author & $\begin{array}{l}\text { Number of patients } \\
\text { (IMN drainage/total number) }\end{array}$ & Follow up & Survival impact \\
\hline Kong AL et al. 2012 & $334 / 1772$ & Nedian 88.8 months difference & Nedian 107-118 months \\
Koo MY et al. 2012 & $88 / 525$ & No difference \\
\hline
\end{tabular}

of other internal comorbidities. Currently, radiotherapy for IMN should be indicated in the case of clinically or pathologically proved involvement of IMN and considered in the case of the presence of combined risk factors such as axillary node involvement, tumors located in inner quadrants and IMN drainage during sentinel node biopsy procedure.

\section{CONFLICT OF INTEREST STATEMENT}

Author's conflict of interest disclosure: None declared.

\section{REFERENCES}

1. Schwartz GF, Giuliano AE, Veronesi U. Proceedings of the consensus conference on the role of sentinel node biopsy in carcinoma of the breast; April 19-22, 2001, Philadelphia, Pennsylvania. Cancer 2002;94:2542-51.

2. Zavagno G, De Salvo GL, Scalco G, Bozza F, Barutta L, Del Bianco P, Renier M, Racano C, Carraro P, Nitti D.; GIVOM Trialists. A randomized clinical trial on sentinel lymph node biopsy versus axillary lymph node dissection in breast cancer: Results of the Sentinella/Givom Trial. Ann Surg 2008:247:207-13.

3. Veronesi U, Paganelli G, Galimberti V, Viale G, Zurrida S, Bedoni M, Costa A, de Cicco C, Geraghty JG, Luini A, Sacchini V, Veronesi P. Sentinel node biopsy to avoid axillary dissection in breast cancer with clinically negative lymph nodes. Lancet 1997;349:1864-7.

4. Krag DN, Anderson SJ, Julian TB, Brown AM, Harlow SP, Costantino JP, Ashikaga T, Weaver DL, Mamounas EP, Jalovec LM, Frazier TG, Noyes RD, Robidoux A, Scarth HM, Wolmark N.Sentinel-lymph-node resection compared with conventional axillary-lymph-node dissection in clinically node-negative patients with breast cancer: overall survival findings from the NSABP B-32 randomised phase 3 trial. Lancet Oncol 2010;11(10):927-33.

5. Veronesi U, Paganelli G, Viale G, Luini A, Zurrida S, Galimberti V, Intra M, Veronesi P, Robertson C, Maisonneuve P, Renne G, De Cicco C, De Lucia F, Gennari R. A randomized comparison of sentinel-node biopsy with routine axillary dissection in breast cancer. N Engl J Med 2003;349:546-53.
6. Sarvi M, Mehta P, Vallow L. Is nodal irradiation necessary in breast cancer patients with positive sentinel node biopsy without axillary dissection. Int J Radiat Oncol Biol Phys 2002;54:232-3.

7. Veronesi U, Valagussa P.Inefficacy of internal mammary nodes dissection in breast cancer surgery. Cancer 1981:47:170-5.

8. Sarvi M, Mehta P, Vallow L. Is nodal irradiation necessary in breast cancer patients with positive sentinel node biopsy without axillary dissection. Int J Radiat Oncol Biol Phys 2002:54:232-3.

9. Veronesi U, Valagussa P. Inefficacy of internal mammary nodes dissection in breast cancer surgery. Cancer 1981:47:170-5.

10. Jansen L, Doting MH, Rutgers EJ, de Vries J, Olmos RA, Nieweg OE. Clinical relevance of sentinel lymph nodes outside the axilla in patients with breast cancer. Br J Surg 2000;87:920-5.

11. Fisher B, Slack NH, Cavanaugh PJ, Gardner B, Ravdin RG. Postoperative radiotherapy in the treatment of breast cancer: Results of the NSABP Clinical Trial. Ann Surg 1970:172:711-32.

12. Cox EF, Buxton RW. Internal mammary lymph node biopsy as a guide to postmastectomy radiation therapy in breast carcinoma. Am Surg 1960;26:335-40.

13. Cody HS, 3rd, Urban JA. Internal mammary node status: a major prognosticator in axillary node-negative breast cancer. Ann Surg Oncol 1995;2:32-7.

14. Sohn VY, Arthurs ZM, Sebesta JA, Brown TA. Primary tumor location impacts breast cancer survival. Am J Surg 2008;195(5):641-4.

15. Colleoni M, Zahrieh D, Gelber RD, Holmberg SB, Mattsson JE, Rudenstam CM, Lindtner J, Erzen D, Snyder R, Collins J, Fey MF, Thürlimann B, Crivellari D, Murray E, Mendiola C, Pagani O, Castiglione-Gertsch M, Coates AS, Price K, Goldhirsch A. Site of primary tumor has a prognostic role in operable breast cancer: the international breast cancer study group experience. J Clin Oncol 2005;23(7):1390-400.

16. Donegan WL. The influence of untreated internal mammary metastases upon the course of mammary cancer. Cancer 1977;39(2):533-8.

17. Correa CR, Litt HI, Hwang WT, Ferrari VA, Solin LJ, Harris EE. Coronary Artery Findings After Left-Sided Compared With Right-Sided Radiation Treatment for Early-Stage Breast Cancer. J Clin Oncol 2007:25:3031-7.

18. Gagliardi G, Constine LS, Moiseenko V, Correa C, Pierce LJ, Allen AM, Marks LB. Radiation Dose-Volume Effects in the Heart. Int J Radiat Oncol Biol Phys 2010;76(3 Suppl):S77-85.

19. Early Breast Cancer Trialists' Collaborative Group. Effects of radiotherapy and of differences in the extent of surgery for early breast cancer on local recurrence and 15-year survival: An overview of the randomized trials. Lancet 2005;366:2087-106. 
20. Paszat LF, Vallis KA, Benk VM, Groome PA, Mackillop WJ, Wielgosz A. A population-based case-cohort study of the risk of myocardia infarction following radiation therapy for breast cancer. Radiother Oncol 2007;82:294-300.

21. Darby SC, McGale P, Taylor CW, Peto R. Long-term mortality from heart disease and lung cancer after radiotherapy for early breast cancer: Prospective cohort study of about 300,000 women in US SEER cancer registries. Lancet Oncol 2005;6:557-65.

22. Paszat LF, Mackillop WJ, Groome PA, Schulze K, Holowaty E. Mortality from myocardial infarction following postlumpectomy radiotherapy for breast cancer: A population-based study in Ontario, Canada. Int J Radiat Oncol Biol Phys 1999;43:755-61.

23. Hooning MJ, Botma A, Aleman BM, Baaijens MH, Bartelink H, Klijn JG, Taylor CW, van Leeuwen FE. Long-term risk of cardiovascular disease in 10-year survivors of breast cancer. J Natl Cancer Inst 2007;99:36575.

24. Heuts EM, van der Ent FW, von Meyenfeldt MF, Voogd AC. Internal mammary lymph drainage and sentinel node biopsy in breast cancer - A study on 1008 patients. Eur J Surg Oncol 2009;35(3):252-7.

25. Veronesi U, Arnone $P$, Veronesi $P$, Galimberti V, Luini A, Rotmensz N, Botteri E, Ivaldi GB, Leonardi MC, Viale G, Sagona A, Paganell $\mathrm{G}$, Panzeri R, Orecchia $\mathrm{R}$. The value of radiotherapy on metastatic internal mammary nodes in breast cancer: Results on a large series. Ann Oncol 2008;19:1553-60.

26. Farrús $B$, Vidal-Sicart $S$, Velasco $M$, Zanón $G$, Fernández $P L$, Muñoz M, Santamaría G, Albanell J, Biete A. Incidence of internal mammary node metastases after a sentinel lymph node technique in breast cancer and its implication in the radiotherapy plan. Int Radiat Oncol Biol Phys 2004;60:715-21.

27. Ramsay SC, Cassidy N, Meade S. Clinically node-negative breast cancer, internal mammary lymph nodes, and sentinel lymph node biopsy. Clin Nucl Med 2008;33:391-93.

28. Livingston S F, Arlen M. The extended extrapleural radical mastectomy: its role in the treatment of carcinoma of the breast. Ann Surg 1974; 179(3): 260-5.

29. Urban JA, Marjani MA. Significance of internal mammary lymph node metastasis in breast cancer. Am J Roentgenol Radium Ther Nucl Med 1971;3:130-6.

30. Coombs NJ, Boyages J, French JR, Ung OA. Internal mammary sentinel nodes: ignore, irradiate or operate? Eur J Cancer 2009;45:789-94.

31. Hindié E, Groheux D, Hennequin C, Zanotti-Fregonara $P$ Vercellino L, Berenger N, Toubert ME, Maylin C, Vilcoq JR, Espié M. Lymphoscintigraphy can select breast cancer patients for internal mammary chain radiotherapy. Int J Radiat Oncol Biol Phys 2012;83(4):1081-8

32. Zeng J, Xie H, Lu Y, Feng Z, Li F. Clinical Implications of Micrometastasis Detection in Internal Mammary Nodes of Breast Cancer Patients. Breast Care (Basel) 2012;7(3):216-9.

33. Postma EL, Van Wieringen S, Hobbelink MG, Verkooijen HM, Van den Bongard HJGD, Borel Rinkes IHM, Witkamp AJ. Sentinel lymph node biopsy of the internal mammary chain in breast cancer. Breast Cancer Res Treat 2012;134(2):735-41.

34. Leidenius $M H$, Krogerus LA, Toivonen TS, Leppänen EA, von Smitten KA. The clinical value of parasternal sentinel node biopsy in breast cancer. Ann Surg Oncol 2006;13:321-6.

35. Galimberti V, Veronesi P, Arnone P, De Cicco C, Renne G, Intra M, Zurrida S, Sacchini V, Gennari R, Vento A, Luini A, Veronesi U. Stage migration after biopsy of internal mammary chain lymph nodes in breast cancer patients. Ann Surg Oncol 2002;9(9):924-8.

36. Van der Ent FW, Kengen RA, van der Pol HA, Povel JA, Stroeken HJ, Hoofwijk AG. Halsted revisited: internal mammary sentinel lymph node biopsy in breast cancer. Ann Surg 2001;234.

37. Huang O, Wang L, Shen K, Lin H, Hu Z, Liu G, Wu J, Lu J, Shao Z, Han $Q$, Shen Z. Breast cancer subpopulation with high risk of interna mammary lymph nodes metastasis: analysis of 2,269 Chinese breast cancer patients treated with extended radical mastectomy. Breast Cancer Res Treat 2008;107(3):379-87.

38. Chen RC, Lin NU, Golshan M, Harris JR, Bellon JR. Internal mammary nodes in breast cancer: diagnosis and implications for patient management: a systematic review. J Clin Oncol 2008;26:4981-9.

39. Zhang YJ, Oh JL, Whitman GJ, lyengar P, Yu TK, Tereffe W, Woodward WA, Perkins G, Buchholz TA, Strom EA. Clinically apparent internal mammary nodal metastasis in patients with advanced breast cancer: incidence and local control. Int J Radiat Oncol Biol Phys 2010;77(4):1113-9.

40. Paredes $P$, Vidal-Sicart S, Zanón G, Pahisa J, Fernández PL, Velasco M, Santamaría G, Ortín J, Duch J, Pons F. Clinical relevance of sentinel lymph nodes in the internal mammary chain in breast cancer patients. Eur J Nucl Med Mol Imaging 2005;32(11):1283-7.

41. Sarp S, Fioretta G, Verkooijen HM, Vlastos G, Rapiti E, Schubert H, Sappino AP, Bouchardy C. Tumor location of the lower-inner quadrant is associated with an impaired survival for women with earlystage breast cancer. Ann Surg Oncol 2007;14(3):1031-9.

42. Bräutigam E, Track C, Seewald DH, Feichtinger J, Spiegl K, Hammer J. Medial tumor localization in breast cancer-an unappreciated risk factor? Strahlenther Onkol 2009;185(10):663-8. doi: 10.1007/s00066009-1984-x

43. Veronesi U, Marubini E, Mariani L, Valagussa P, Zucali R. The dissection of internal mammary nodes does not improve the survival of breast cancer patients. 30-year results of a randomised trial. Eur J Cancer 1999;35:1320-5.

44. Cody HS. 3rd Clinical significance and management of extra-axillary sentinel lymph nodes: worthwhile or irrelevant? Surg Oncol Clin N Am 2010;19:507-17.

45. Olson RA, Woods R, Speers C, Lau J, Lo A, Truong PT, Tyldesley S, Olivotto IA, Weir L. Does the intent to irradiate the internal mammary nodes impact survival in women with breast cancer? A populationbased analysis in British Columbia. Int J Radiat Oncol Biol Phys 2012;83(1):35-41

46. Fowble B, Hanlon A, Freedman G, Nicolaou N, Hoffman J, Sigurdson E, Boraas M, Torosian M, Goldstein L. Internal mammary node irradiation neither decreases distant metastases nor improves survival in stage I and II breast cancer. Int J Radiat Oncol Biol Phys 2000;47(4):883-94.

47. Kong AL, Tereffe W, Hunt KK, Yi M, Kang T, Weatherspoon K, Mittendorf EA, Bedrosian I, Hwang RF, Babiera GV, Buchholz TA, MericBernstam F. Impact of internal mammary lymph node drainage identified by preoperative lymphoscintigraphy on outcomes in patients with stage I to III breast cancer. Cancer 2012;118(24):6287-96.

48. Stemmer SM, Rizel S, Hardan I, Adamo A, Neumann A, Goffman J, Brenner $\mathrm{HJ}$, Pfeffer MR. The role of irradiation of the internal mammary lymph nodes in high-risk stage II to IIIA breast cancer patients after high-dose chemotherapy: a prospective sequential nonrandomized study. J Clin Oncol 2003;21(14):2713-8.

49. Koo MY, Lee SK, Bae SY, Choi MY, Cho DH, Kim S, Lee JE, Nam SJ, Yang JH. Long-term outcome of internal mammary lymph node detected by lymphoscintigraphy in early breast cancer. J Breast Cancer 2012(1):98-104

50. Fisher B, Redmond C, Fisher ER, Bauer M, Wolmark N, Wickerham DL, Deutsch M, Montague E, Margolese R, Foster R. Ten-year results of a randomized clinical trial comparing radical mastectomy and total mastectomy with or without radiation. $\mathrm{N}$ Engl J Med 1985;312(11):674-81.

51. Arriagada R, Lê MG, Rochard F, Contesso G. Conservative treatment versus mastectomy in early breast cancer: patterns of failure with 15 years of follow-up data. Institut Gustave-Roussy Breast Cancer Group. J Clin Oncol 1996;14(5):1558-64. 